\title{
Foresight-audit of management's systems in aerospace engineering
}

\author{
Irina Gorelova ${ }^{1, *}$, Ekaterina Harchevnikova ${ }^{1}$, and Maryam Minigalieva ${ }^{2}$ \\ ${ }^{1}$ Russian Academy of national economy and public administration under the President of the Russian \\ Federation, Volgograd Institute of management, 400131 Volgograd, Russia \\ ${ }^{2}$ Ugra State University, Pedagogy Department, 628012 Khanty-Mansiysk, Khanty-Mansi \\ Autonomous Area - Yugra, Russia
}

\begin{abstract}
Space engineering is an intensively developing sphere of human activity. The tasks of managing this sphere include the functions of designing and forecasting the future, as well as evaluating the predicted achievements and successes required for implementation, as well as possible disruptions and problems in the aerospace industry and resources. The evaluation of these resources acts as foresight audit. Foresight audit is a comprehensive internal and external assessment of the dynamic and static capabilities of aerospace companies. Foresight audit includes assessment of economic, social, organizational, psychological ideological and other aspects of the functioning and development of aerospace enterprises. The purpose of the study is the functions of designing and forecasting the future, as well as evaluating the predicted achievements and successes required for implementation, as well as possible disruptions and problems in the aerospace industry and resources. The cosmos will be "mastered" only with the mastering of oneself by man, only when harmony of man and the world is reached.
\end{abstract}

\section{Introduction}

Space engineering is an intensively developing sphere of human activity. Most important tasks of managing in the Space industry include the functions of designing and forecasting the future. Other tasks of managing in this sphere include the evaluating the predicted achievements and successes required for implementation, as well as the evaluating of the possible disruptions and problems in the aerospace industry and resources. The evaluation of these resources acts as foresight audit. Foresight audit is a comprehensive internal and external assessment of the dynamic and static capabilities of aerospace companies. Foresight audit includes assessment of economic, social, organizational, psychological ideological and other aspects of the functioning and development of aerospace enterprises. Leading aspects of foresight are aspects related to the study of the «human factor» of the current and predicted success of aerospace enterprises. To such aspects, it is possible to carry features and strategy of motivation of work. It is activity of the experts working at the enterprises of an aerospace branch and strategy of professional

\footnotetext{
*Corresponding author: mariam ira@mail.ru
} 
and career development of experts of branch as a whole. This can also include the features of management systems for enterprises in the aerospace industry, the notion of enterprises as organizations with mono-subjective (mono-actor) or intersubjective management (multiactor). In addition, this is the view of the aerospace industry as a sphere of development and application of multi-agent technologies. Multi-agent technologies are the complex set of computer programs. Multi-agent technologies is included in the industry management system in general and in the particular aspects of this industry.

\section{Materials and Methods}

The primary method is theoretical integrative analysis. Of particular interest is the functions of designing and forecasting the future. Other tasks of managing in this sphere include the evaluating the predicted achievements and successes required for implementation, as well as the evaluating of the possible disruptions and problems in the aerospace industry and resources. The evaluation of these resources acts as foresight-audit. The authors discusses various aspects of the functions of designing and forecasting the future. The strategic management theory sees the source of competitive advantage in dynamic and static abilities, forecasting the future and the predicted achievements and successes required for implementation.

\section{Results}

The current problems of aerospace companies say that this industry is at the breaking point of its development. It needs an integrative foresight audit (multi-level and multi-component ore system audits) and audits of their current operations. The integrated foresight audit of aerospace companies is aimed at assessing the prospects and challenges, barriers and challenges of the industry development that are possible in the more or less distant future. Its purpose is to analyze the static and dynamic resources of enterprises, their management systems and execution. Also, it is aimed at developing scenarios for the near future, assessing the joker and «black swans». These uncommonly «artefacts» knits both with the human factor, and with the development of the world of technology, culture and the transformations of the natural world. The aerospace field also cannot develop without a clear understanding of its purpose and mission: ideological and moral support of life. The current crisis in the aerospace industry is due precisely to the fact that these pillars proved is much destroy. The fact is that humankind has lost an understanding of why the humankind needs space. As a result, there are numerous problems and accidents.

\section{Discussion}

Perception of the cosmos as another sphere of development, conquest of nature has led a person to a dead end. As K.E. Tsiolkovskiy noted, the Earth is the cradle of humankind. But man cannot always remain in the cradle. Space is the place and time of development not just «exploitation and development». Man is mastering himself, not space itself. And he can master it, only being a cosmic being. Only when man recognizes himself as a cosmic being involved in the development of the entire universe, he does acquire the moral right and meaning of entering into the «great cosmos». On the contrary, closing in on pragmatics, for example, trade in space territories, research conducted within the framework of corporate requests, which are only interested in financial benefits and social control, a person will not be able to advance into space. Moreover, he begins to suffer on the Earth. These are the place and time, in which he ceases to be a man-inhabitant of the Earth, a part of nature and 
culture, but becomes an automaton the part of the technologies. Attitude towards man as an impersonal automaton, so typical for the end of the XX and beginning of the XXI century, destroys the meaning of the development and existence of the aerospace industry. Especially negatively among the aerospace industry, the development of the industry is badly influenced by educational institutions that train inadequately competent specialists As a result, we have an uneven, crisis-evolving industry. In this industry, we have conquests and achievements alternate with breakdowns in accidents. Thus, the motivation of specialists in the aerospace industry, their professional and career development, is a general management of aerospace enterprises. However, it is far from perfect on the one hand, and far from understanding their purpose and mission on the other. Indeed, one cannot strive for anything unknown, and perfection is always relative. It also determines their final state and results, as well as the ways to achieve this state, the results. K.E. Tsiolkovskiy, other philosophers and cosmic scientists talked about this even more fully and definitely.

K.E. Tsiolkovskiy considered civilization as a single organism that undergoes several phases in the development. Each of phases is associated with the formation of new, more realistic and detailed ideas about happiness, the value of human life, the conditions of its implementation and meaning, as well as the transformation of man: immortalism (immortality), victory over time and autotrophy, victory over space, «interplanetarism» (interplanetary life). «For life in space, man and humankind need a new degree of development, a new-another-understanding of oneself and the world. The idea of the relationship between man and the cosmos was reflect in his cosmic philosophy: «The whole cosmos determines our life», he noted, «everything is continuous and everything is one ... It is hard to imagine that any part of it (the cosmos) sooner or later had no influence on us». «The universe would not have made sense if it had not been filled with an organic, sensible, sensible world [1]. Part of his work is his «cosmic ethics», which includes the development of ethical foundations of contacts with aliens, the recognition of the need for joint labor for the transformation of outer space. Exit to space expanses is an important aspect of the evolution of humankind, and the ideas of autotrophy, self-feeding of humankind, the connection of man and the universe, developed by K.E. Tsiolkovskiy, followed by V.I. Vernadskiy [2].

The emergence of man is an act of the greatest importance, a single during the geological history: he does not have anything analogous in the environment of the myriads of the preceding centuries [2]. At the same time, «The progress of organisms is continuous and therefore can not stop at a person», asserted K.E. Tsiolkovskiy; «Man is not» the crown of creation», In V.I. Vernadskiy thought, consciousness and life in their modern form must inevitably be followed by «super-consciousness» and «super-life» [2]. K.E. Tsiolkovskiy spoke about the future man, the «animal of the cosmos», directly assimilating in its nutrition the sun's rays and elementary substances of the environment and can be immortal. He and V.I. Vernadskiy stressed the importance of autotrophy «The consequences of such a phenomenon in the mechanism of the biosphere would be enormous. This would mean that a single whole - life - would again be divided, a third, independent branch would appear ... The human mind in this way would not only create a new great social achievement, but would introduce a new great geological achievement into the mechanism of the biosphere ... » [2]. In this case, K.E. Tsiolkovskiy takes life as a "circuit". He notes the helicity of life. This is for him the most common type of development. He distinguishes in it as stages of an ascending, more complicated development, as well as the stages of the subsequent "decomposition", "simplification", a return to a more elementary form. Further, after them follow the stages of the new revolution. There is an even greater complication, and then an even greater simplification, and so on - to infinity. K.E. Tsiolkovskiy develops the idea of $\mathrm{N}$. Fedorov about the interconnectedness and interdependence of humankind's victories over space and over time. Immortality is possible only in outer space, infinite and 
inexhaustible in its energy and material resources. Only immortal creatures with an essentially transformed organism and the awareness of themselves and the world can survive in a variety of extraterrestrial environments, master and transform the Universe. Later, in V.A. Sukhovo-Kobylin described the active evolution of man, aimed at the cosmic expansion of humankind. This transformation presupposes «an infinite involution ... into oneself, deeper into» self-consciousness, up to such a «connection with oneself», such a spiritualization that this future organism becomes, as it were, spatial, supersensible («until the flesh disappears»), «Ethereal». This is very similar to the idea of the future «ray» humanity in the «theory of cosmic eras» by K. E. Tsiolkovskiy [3]. However, in their understanding, the cosmic nature of the phenomena of life and man, the demand for human activity in relation to the macrocosm, was combine with the natural rootedness of this life. So, V.I. Vernadskiy writes about the principle of F. Redi. «F. Redi claimed: every living organism comes from another living the same organism»[2]. He notes «Spontaneous generation that is, the genesis of a living organism due to inert matter, without the mediation of another living organism, is still seemingly logical for many scientists ... for a scientific explanation of life. With deep faith, beliefs are expressed that the direct synthesis of the organism from its material elements must be a necessary completion of the development of science. "However, in his opinion», of course, it is possible that they correspond to reality. You cannot consider them scientifically refuted. However, nothing indicates their likelihood. Nothing also indicates that the problem of spontaneous generation does not belong to the same series of searches as the problem of quadrature of the circle, the trisection of the angle, the «perpetuum» mobile, the philosophical stone». However, «The desire to resolve all these problems was not fruitless, it had very important consequences. It led to great new discoveries, but the most problems turned out to be unrealistic» [2]. K.E. Tsiolkovskiy considered civilization as a single organism, which takes several stages in development. In his opinion, humankind cannot «live forever in the cradle», and the output into the near-Earth space becomes the second (after the embryonic) phase of the evolution of humankind. This raises the question of the unity of the «terrestrial» and «extra-terrestrial» humankind (all «neo-humanity») and reproduction, the reproduction of man in space. «Space activity can be contrasted with the earthly and demand the formation of other ideas about happiness, the value of human life, the conditions of its implementation and meaning» [3]. The third phase is the resettlement of people throughout the Galaxy, where in time people will become truly «cosmic animals», that is, they can live without special means of protection in an open space: they need a new degree of development, and peace $[4,5]$. On the way to this understanding, to a new awareness of yourself and the world. In the opinion of K.E. Tsiolkovskiy, «The coming thousands and millions of years will improve the nature of man and his social organization. Humankind will turn as if into one powerful being» [3]. «There will come an unification, they will cease due to this war, since there will be no one to fight with. The happy social order, prompted by geniuses, will force technology and science to go forward with unimaginable speed and with the same speed to improve human life. ... There will be full scope for the development of both public and individual properties of a person that does not harm people», K.E. Tsiolkovskiy wrote [3]. The ethics of the conscious beings of the cosmos, according to K.E. Tsiolkovskiy, «consists in that there is nowhere any suffering: neither for the perfect, nor for other immature, or beginnings animals» [5]. He noted the importance of «space selection», wrote that it is necessary to strive for a painless repayment of the life of unsuccessful genetically humans and animals, to improve them by encouraging the birth of more perfect and to charity towards everything imperfect, to animals, and humans [6]. He also believed that all particles of the universe have infinite complexity: the universe has developed or complicated for an infinite time, that is why for the person there are and can be accessed the most diverse materials of different infinitely 
removed from today, including «parallel existing» worlds and epochs. This will lead to the fact that a person realizes not only his multiplicity and infinity «in itself», but also his own dialogue and unity with the world. L.M. Gindilis noted that an important part of the concept of K.E. Tsiolkovskiy «is the notion that civilizations do not develop in isolation, but in close cooperation, to which new members, new communities of sentient beings join as they develop. This public organization is built on a hierarchical principle. «Unions of the nearest suns are formed, unions of unions, etc. Where the limit to these alliances is difficult to say, since the universe is infinite» [7]. He also did not exclude the possibility of hidden contact phenomena, visits and interference of highly developed civilizations in earthly affairs. «Sometimes we see unusual phenomena», he wrote. "Are they the result of the activity of surviving sentient beings of other epochs» and other more developed and perfect civilizations?» [7]. All this suggests that K.E. Tsiolkovskiy and Russian cosmism as a phenomenon was a philosophy of action and faith: faith in God as a belief in Life was backed up by scientific research and data that would not be «deciphered» at first, and probably, not even in this century. However, the enormity of the problems raised and solved by the Russian cosmos builds the way for other sciences and research that do not exist nowadays, which modern humankind sometimes does not even guess.

\section{Conclusions}

Thus, aerospace enterprises in the modern world badly need to conduct a serious "foresightaudit", an external and internal audit of their being and development. Such an audit is necessary at the level of values, goals and mission of their life. Such an audit was also need at the level of the management system of aerospace enterprises and groups of specialists and individual specialists. External and internal audit is necessary for that. To assess the static dynamic aspects of aerospace enterprises, including the static and dynamic capabilities of enterprise managers. It is also very important to assess the prospects and limitations of development at the level of each individual specialist. Time and place, when the aerospace enterprises could afford a "generalized", impersonal and morally pointless approach, do not exist anymore. The cosmos will be "mastered" only with the mastering of oneself by man, only when harmony of man and the world is reached [8].

\section{References}

1. K. E. Tsiolkovskiy, Mechty o Zemle i nebe [In Russian] (Tula: Priokskoe knijnoe izdatelstvo, 1986)

2. A. V. Sukhovo-Kobylin, Filosofiya dukha ili sotsiologiya. Russkiy kosmizm: antologiya filosofskoy mysli (Moscow: Pedagogika-Press, 1993)

3. A. A. Medenkov, M. A. Milovanova, N. L. Fetisova, Filosofskiye problemy mezhplanetnykh poletov. Idei K.E. Tsiolkovskogo: proshloye, nastoyashcheye, budushcheye. XLVII Nauchnyye chteniya (Kaluga: K.E. Tsiolkovskiy CDSH, 2012)

4. O. Gazenko, Kosmonavt dolzhen ostavat'sya chelovekom Zemli [In Russian], Science and Life 4, 24 (2006)

5. K. E. Tsiolkovskiy, Ocherki o Vselennoy [In Russian] (Kaluga: The Golden Alley, 2001)

6. K. E. Tsiolkovskiy, Kosmicheskaya filosofiya [In Russian] (Moscow: URSS, 2001)

7. K. E. Tsiolkovskiy, Kosmicheskaya filosofiya. Archive of the USSR [In Russian] (Moscow: Academy of Sciences, 1935)

8. M. R. Arpentieva, Ksenopsikhoterapiya [In Russian], Philosophy \& Cosmology 1(15), 163 (2016) 